\section{MS32-P19 Oleanolic Acid: A Case Study of the Control and Suppression of Solvate Crystals and its Potential for Chiral Resolution}

\author{
REBECCA YIP ${ }^{1}$, Thanh-ha Nguyen ${ }^{1}$, Yuxin Zhang $^{1}$, Herman \\ H.Y. Sung ${ }^{1}$, Ian D. Williams ${ }^{1}$
}

\section{Hong Kong University of Science and Technology (HKUST)}

email: reyip1992@live.co.uk

Oleanolic Acid (OA-H) a natural triterpene of pharmaceutical interest has been found to form solvate crystals from a wide range of solvents.[1][2] The control of solvate versus anhydrous phase formation is demonstrated for a varierty of alcohols, with characterization by pXRD, TGA and single-crystal XRD. It appears that the product formation can be correlated to the temperature of crystallization.

OA-H has also demonstrated the ability to form diastereomeric salts with various amines, in particular the formation of diastereomeric salts of OA-H with racemic amines for the purpose of chiral resolutions have been studied. Following on from the solvate phases prepared and the potential of OA-H to form cocrystals with other chiral compounds, the potential of $\mathrm{OA}-\mathrm{H}$ as a resolving agent for a variety of chiral alcohols has also been explored with promising results.

[1] Tong, H. Y.; Wu, H. B., Zheng, Y., Xi, J., Chow, A. h. 1., Chan, C. K. Int. J. Pharm. 2008, 355, 195-202.

[2] Froelich, A.; Gzella, A. K., Acta Crystallogr E 2010, 66, o2690.

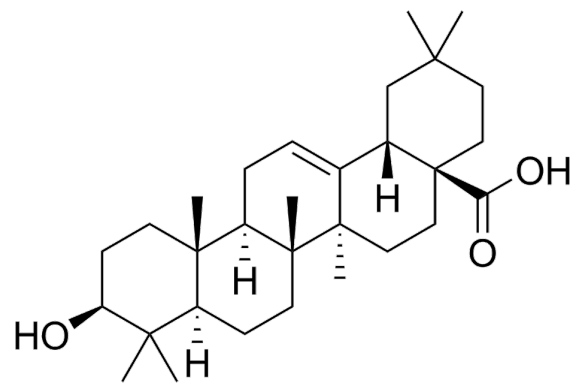

Figure 1. Oleanolic Acid Structure

Keywords: Solvates, cocrystals, chiral resolution

\section{MS32-P20 From 0D to 3D - The structural diversity of polyoxometalate catalysts}

Kim D. von Allmen ${ }^{1,2}$, Anthony Linden ${ }^{1}$, Greta R. Patzke*1

1. University of Zurich, Departement of Chemistry

2. Empa Swiss Federal Laboratories for Materials Science and Technology, Center for X-ray Analytics

email: kim.vonallmen@empa.ch

Polyoxometalates (POMs) are metal oxo clusters which are preferably formed by $\mathrm{W}, \mathrm{Mo}$ and $\mathrm{V}$ in their high oxidation states. Among their remarkable spectrum of potential applications, POMs have widely been investigated as homogeneous and heterogeneous catalysts for organic reactions and as catalysts for artificial photosynthesis.[1] It was shown that the extent of $\mathrm{Co} / \mathrm{W}$ disorder in the transition metal core of $\mathrm{Co} / \mathrm{Bi}$-sandwich type POMs based on the lacunary precursor $\mathrm{Na}_{9}\left[\mathrm{~B}-\alpha-\mathrm{BiW}_{9} \mathrm{O}_{33}\right]$ is a key feature for their activity as water oxidation catalysts (WOCs).[2] In order to understand the origin of the catalytic activity, POMs were prepared from $\mathrm{Na}_{9}\left[\mathrm{~B}-\alpha-\mathrm{BiW}_{9} \mathrm{O}_{33}\right]$ in the presence of $\mathrm{Mn}$ (II), $\mathrm{Co}$ (II), and $\mathrm{Cu}$ (II) cations. Efforts were made to prepare compounds with a specific composition of the transition metal core. Single crystal X-ray diffraction studies of the new transition metal containing POMs have revealed a large structural diversity of polyanions, which is due to $\alpha-\beta$ isomerization and partial decomposition of the lacunary precursor. Cross-linking of polyanions via supplementary d- or f-block counter cations resulted in the formation of $1 \mathrm{D}, 2 \mathrm{D}$, and even 3D networks.[3] The polyanion $\left[\mathrm{Cu}_{2}\left(\mathrm{H}_{2} \mathrm{O}\right)_{4}\left(\mathrm{~B}-\beta-\mathrm{BiW}_{10} \mathrm{O}_{35}\right)_{2}\right]^{10-}$ crystallized with a $2 \mathrm{D}$ structure in the presence of $\mathrm{Na}^{+}$and $\mathrm{K}^{+}$cations, while $\mathrm{Rb}^{+}$cations favored the crystallization of the $0 \mathrm{D}$ structure $\mathrm{Na}_{6} \mathrm{Rb}_{6}\left[\mathrm{Cu}_{3}\left(\mathrm{H}_{2} \mathrm{O}\right)_{3}\left(\mathrm{~B}-\alpha-\mathrm{BiW}_{9} \mathrm{O}_{33}\right)_{2}\right]$ from the same reaction mixture. The importance of the counter cations as structure-directing parameter could thus be highlighted.

The negative charge of polyanions can be exploited to prepare new compounds with interesting properties by introducing of a transition metal complex as the counter cation. Crystals could be grown from $\left[\mathrm{Mn}_{3}\left(\mathrm{H}_{2} \mathrm{O}\right)_{3}\left\{\mathrm{As}_{2} \mathrm{~W}_{18} \mathrm{O}_{66}\right\}\right]^{8-}$ as a potential WOC and the photosensitizer cation ${ }^{2}\left[\mathrm{Ru}(\mathrm{bpy})_{3}\right]^{2+}$. Crystal structure determination confirmed the formation of $\left[\mathrm{Ru}(\mathrm{bpy})_{3}\right]_{4}\left[\mathrm{Mn}_{3}\left(\mathrm{H}_{2} \mathrm{O}\right)_{3}\left\{\mathrm{As}_{2} \mathrm{~W}_{18} \mathrm{O}_{66}\right\}\right]$ from which crucial structural details could be deduced.

[1] D.-L. Long, R. Tsunashima, L. Cronin, Angew. Chem. Int. Ed. 2010, 49, 1736. [2] F. Evangelisti, P.-E. Car, O. Blacque, G. R. Patzke, Catal. Sci. Technol. 2013, 3, 3117. [3] K. von Allmen, H. Grundmann, A. Linden, G. R. Patzke, in preparation for submission. 